\section{Discussion}

It has been previously suggested that any weight-reducing effect of phenformin in non-diabetic obese patients is confined to those with a family history of diabetes (Roginsky and Sandler, 1968). The present study, however, shows that both phenformin and metformin, when given in substantial dosage, have weight-reducing properties in non-diabetic patients, irrespective of the family history.

Some of the weight loss may have resulted from reduced food intake; the nature of the study was such that almost all patients receiving a diguanide experienced either nausea or anorexia, but these were either transient or abolished by appropriate reduction of the daily dosage. Other alternatives include the possibility that diguanide treatment causes a reduction in alimentary absorption of glucose, but the present evidence for this is conflicting (Czyzyk et al., 1968 ; Pedersen and Olesen, 1968). If reduction in food intake or food absorption is not the cause of the weight loss then treatment with diguanides may accelerate some catabolic process. It has been shown that they increase the peripheral utilization of glucose in the non-diabetic (Searle and Cavalieri, 1968 ; Kreisberg, 1968). This finding, however, has not been confirmed by others (Butterfield and Whichelow, 1968). The cause of the weight loss cannot be established until the various effects of the diguanides have been more fully elucidated.

From the practical point of view the mean weight loss during diguanide treatment was similar to that obtained by dextroamphetamine and some of its congeners in comparable patients with refractory obesity (Duncan et al., 1960 ; Seaton et al., 1961, 1964a, 1964b; Munro et al., 1966). As with these drugs, the weight-reducing effect of the diguanide may be temporary, but a longer study is required to establish this point. There is clearly no danger of central nervous system stimulation or addiction with diguanide treatment, but it is not without hazard, particularly in patients with appreciable renal, hepatic, or cardiovascular disease, since lactic acidosis can occur and fatalities have been attributed to phenformin administration (Tranquada et al., 1963 ; Young and Armanino, 1965 ; Proctor and Stowers, 1967). One patient in the present study had a significant fall in serum bicarbonate; though this may not reflect a rising serum lactate level, it would seem prudent to monitor serum bicarbonate levels at least while the dose of diguanide is being increased.

\section{REFERENCES}

Butterfield, W. J. H., and Whichelow, M. J. (1968). Lancet, 2, 785. Clarke, B. F., and Duncan, L. J. P. (1968). Lancet, 1, 123. Czyzyk, A., Tawecki, J., Sadowski, J., Ponikowska, I., and Szezepanik, Z. (1968). Diabetes, 17, 492.

Duncan, L. J. P., Rose, K., and Meiklejohn, A. P. (1960). Lancet, 1, 1262 .

Kreisberg, R. A. (1968). Diabetes, 17, 481.

Munro, J. F., Seaton, D. A., and Duncan, L. J. P. (1966). British

, J., and Olesen, E. S. (1968). Acta endocrinologica, 57, 683 Proctor, D. W., and Stowers, J. M. (1967). British Medical Fournal, 4, 216.

Roginsky, M. S., and Sandler, J. (1968). Annals of the New York Academy of Sciences, 148, 892 .

Searle, G. L., and Cavalieri, R. R. (1968). Annals of the New York

Academy of Sciences, 148, 734.
Seaton, D. A., Duncan, L. J. P., Rose, K., and Scott, A. M. (1961). British Medical fournal, 1, 1009.

Seaton, D. A., Rose, K., and Duncan, L. J. P. (1964a). Scottish Medical fournal, 9, 482 .

Seaton, D. A., Rose, K., and Duncan, L. J. P. (1964b). Practitioner, 193, 698.

Siegel, S. (1956). Nonparametric Statistics for the Behavioral Sciences, p. 111. McGraw Hill, New York.

Tranquada, R. E., Bernstein, S., and Martin, H. E. (1963). Fournal of the American Medical Association, 184, 37.

Young, J. M., and Armanino, L. P. (1965). California Medicine, 103, 198.

\title{
Clotting Problems with the Teflon-Silastic Arteriovenous Shunt in Patients on Regular Haemodialysis
}

\author{
M. PAPADIMITRIOU,* M.D. ; R. N. P. CARROLL, $\dagger$ B.SC., F.R.C.S.ED. \\ A. E. KULATILAKE, $\ddagger$ F.R.C.S., F.R.C.S.ED.
}

[With Special Plate Between Pages 32 and 33]

British Medical Fournal, 1969, 2, 15-17

Summary: Episodes of clotting that occurred in 22 ( patients on regular haemodialysis were studied over a six-month period. The venous pressure during dialysis and the radiology of the Teflon-Silastic arteriovenous shunt were found to be satisfactory guides for the management of the shunt. The failure of the shunt during the early stage was mainly due to technical reasons. Histological study of the excised vessels in removed long-term shunts showed that these had failed because of rigidity and thickening of the vessel wall due to calcium and iron deposits or chronic inflammation, or both.

\section{Introduction}

The survival of the arteriovenous Teflon-Silastic shunt of the Scribner type depends on the attention to detail both in tech- nique of insertion and in its subsequent management. Of the many complications that develop-that is, infection, skin necrosis, herniation of the Silastic tubing, and bleeding from the shunt wound-the commonest is clotting (Pendras and Erickson, 1966; Shaldon, 1966; Glashan and Walker, 1968). Repeated resiting of the shunt owing to clotting and total occlusion can be a significant factor in the prognosis of many patients, especially those with hypoplastic blood-vessels. To this end anticoagulants (Wing et al., 1967) and fibrinolytic agents (Anderson et al., 1968 ; Kjellstrand et al., 1968) have been tried successfully in many instances, but these agents are by no means free from side-effects.

* Honorary Registrar and NATO Scholar.

† Surgical Registrar.

¥ Senior Registrar in Urology and Tutor in Surgery.

rtificial Kidney Unit, Department of Surgery, Royal Postgraduate Medical School, Hammersmith Hospital, London W.12. 
We believe that many episodes of clotting can be prevented if the relevant cause is diagnosed early. On the other hand, many complications due to the abuse of anticoagulants can be reduced if these agents are used discriminately.

\section{Material and Methods}

Twenty-two patients (12 males, 10 females) on regular haemodialysis treatment were studied over a six-month period. Eleven were already in the programme (old patients) and 11 new patients were admitted recently. Special attention was paid to the problem of infection (Carroll et al., 1969). All clotting episodes were recorded, the standard declotting procedure was used by a registrar under aseptic conditions, and, when necessary, systemic heparinization of the patient was achieved for 48 to 72 hours. Three of the 22 patients were on long-term anticoagulant therapy with phenindione (Dindevan) owing to repeated clotting episodes.

All the patients were dialysed twice a week for 12 to 14 hours overnight by a modified Kiil artificial kidney with a warm single-pass automatic dialysate supply. A dialysate proportionating machine (J. Lucas Ltd.) was used for monitoring. The venous pressure was recorded as previously described (Papadimitriou and Kulatilake, 1969). The blood flow through the arterial side of the Kiil was measured by the air-bubble method, and recently an ultrasonic probe (Sampson et al., 1969) has been used during each dialysis.

Arteriovenography of the arteriovenous shunt was carried out in patients with low blood flow or repeated minor clotting episodes. Hypaque $60 \%$ was used for each side of the shunt independently to determine the side of primary clotting. When arteriovenous shunts were removed, either as a terminal procedure after transplantation or for replacement, histological studies were carried out. Histological sections were prepared and stained by the standard haematoxylin and eosin method. Iron (Perls, 1867) and calcium (McGee-Russell, 1958) deposits and elastic fibres (Moore, 1951) were also demonstrated.

\section{Results}

The Table shows the number of major clotting episodes during a six-month period in both the old and the new patients. The clotting episodes were more frequent in the second group (57\%). In both groups it was the venous side of the shunt (71\%) that was affected. Reinsertions of the arterial or the venous side of the shunt was performed 2.50 times per month in the old patients and 3.33 times in the new patients. In the first group of patients the mean survival time of the arterial side was 15.4 months and of the venous side 7.4 months. The longest survival of the arterial side was 37 months and of the venous side 22 months in the same patient.
Fig. I shows the pattern followed by the venous pressure in two typical patients who presented with clotting episodes. The first one (A.B.) was running a low venous pressure during dialysis with a low blood flow (clotting of the arterial side), while the second one (C.D.) was running a high venous pressure with a low blood flow (clotting of the venous side). Fig. II shows the normal pattern of the venous pressure of a patient

Major Clotting Episodes of 22 Patients on Regular Haemodialysis During a Six-month Period

\begin{tabular}{|c|c|c|c|c|c|c|c|}
\hline & & & \multirow{2}{*}{ No. } & \multicolumn{3}{|c|}{ Major Clotting Episodes } & \multirow{2}{*}{$\begin{array}{l}\text { Reinser- } \\
\text { tions per } \\
\text { Month }\end{array}$} \\
\hline & & & & Arterial & Venous & Total & \\
\hline $\begin{array}{l}\text { Old patients } . . \\
\text { New patients } .\end{array}$ & $\ldots$ & $\therefore$ & $\begin{array}{l}11 \\
11\end{array}$ & $\begin{array}{l}4 \\
6\end{array}$ & $\begin{array}{l}11 \\
14\end{array}$ & $\begin{array}{l}15 \\
20\end{array}$ & $\begin{array}{l}2 \cdot 50 \\
3 \cdot 33\end{array}$ \\
\hline Total & $\ldots$ & $\ldots$ & 22 & 10 & 25 & 35 & $5 \cdot 83$ \\
\hline
\end{tabular}

(E. F.) in comparison with that of another one (G. H.) who, before the arterial side of his arteriovenous shunt was clotted, presented with unstable and low levels of venous pressure during dialysis. Insertion of a new arterial side led to a high venous pressure, and clotting of the venous side occurred during the next dialysis. A new venous side corrected the abnormal venous pressure and a satisfactory blood flow was achieved. Fig. III shows the effect of anticoagulants in a typical patient (G. H.) with repeated minor clotting episodes at the venous side of the shunt and a high venous pressure during dialysis. Phenindione reduced the venous pressure gradually and further clotting episodes did not occur. When the anticoagulant therapy was discontinued the venous pressure rose again, and on the fifth week clotting of the shunt occurred during the dialysis.

The radiological investigation of shunts with poor function revealed in the main that the Teflon tips were not in alignment with the vessel (Special Plate, Fig. 1). The classical picture of homogeneous narrowing beyond the tip of the venous side of the shunt (Special Plate, Fig. 2) was not so frequently met.

The abnormalities of the arterial side of the shunt were shown by histological examination and consisted mainly of an absent or interrupted endothelium, thickening of the intima (Special Plate, Fig. 3), and rupture or disfigurement of the elastic lamina (Special Plate, Figs. 4 and 5). On the other hand, iron (Special Plate, Fig. 6) and calicum (Special Plate, Fig. 7) deposits were shown in almost every long-standing shunt. The venous side presented with hypertrophy of all layers, formation of clots and recanalization (Special Plate, Fig. 8), chronic inflammation (Fig. 9), and foreign-body-type granuloma around the ligatures (Special Plate, Fig. 10). In those that had technical difficulties in cannulation with stripping of intima there was recanalization and effective blood flow for short periods of time (Special Plate, Fig. 11).
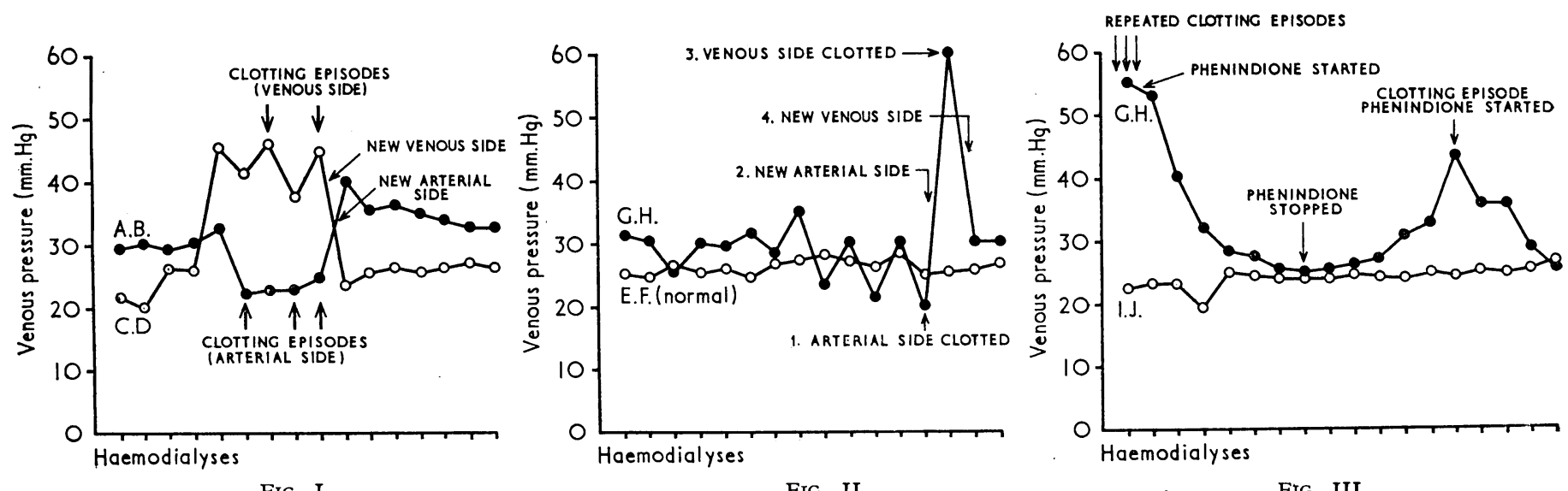

FIG. I

FIG. II

FIG. III

Figs. I, II, and III.-Mean venous pressure during haemodialysis of paticnts with normally functicning shunts (E.F. and I.J.). Clotting episodes on the atterial (A.B.), venous (C.D.), or both sides (G.H.) and effect of anticoagulant therapy on the venous pressure (G.H.). 


\section{Discussion}

Clotting has been the commonest problem in the TeflonSilastic arteriovenous shunts used in patients on regular haemodialysis. Causes of this have already been reported from this unit (Kulatilake, 1966, 1968). Nevertheless, the spontaneous clotting of cannulae is poorly understood at the present time (Pendras and Erickson, 1966), and the occurrence of clotting episodes is sometimes frequent enough to produce anxiety in the patient and continuous attention of the medical staff. Wing et al. (1967) reported one clotting incident every 3.3 patientmonths. We had 5.83 reinsertions monthly, dealing with 22 patients, but, of course, the number of minor clotting episodes was much higher (about three times more). We were reluctant to use anticoagulants because of their known complications, but we have tried to establish criteria and indications for long-term anticoagulation. High $(>45 \mathrm{~mm} . \mathrm{Hg})$ or very low $(<25 \mathrm{~mm}$. $\mathrm{Hg}$ ) venous pressure during the dialysis accompanied by a poor blood flow through the artificial kidney and minor clotting episodes were the main indications for long-term anticoagulant therapy.

Radiology of the shunts was necessary when repeated clotting episodes occurred. The main cause of clotting of the venous side was the poor alignment of the Teflon tip in the vein. On the other hand, abnormalities of alignment, aneurysm formation, or sites of the clot in the arterial component were also diagnosed. The main advantage of radiography was to discover the patency of the vessels, to select suitable sites for recannulation.

Insertion of the cannula itself produces intimal damage and a thin layer of fibrin is deposited on the denuded intima (Glashan and Walker, 1968). This is facilitated by the fact that the blood flow is slower at the periphery of the vessel just beyond the Teflon tip owing to turbulence. Continuing release of thromboplastic substances from the damaged intima during the early stage of cannulation has also been blamed (Glashan and Walker, 1968). The cause of failure in a well-functioning old arteriovenous shunt was not clear. Disfigurement of the elastic lamina, loss of elasticity, and rigidity of the arterial wall due to iron and calcium deposition appear to be the main cause of failure of the arterial side of the shunt. On the other hand, the vein appears to be narrowed from hypertrophy of the intima mainly due to arterialization, though recanalization with formation of tunnels seems to allow a satisfactory blood flow through the shunt. Finally, chronic inflammation and foreign-bodytype granuloma around the ligatures play an important part in the survival of the shunt. Long-term anticoagulation seems to prolong considerably the survival of the arteriovenous shunt (Wing et al., 1967 ; Kulatilake, 1966).

Kulatilake (1968) described the case of a patient with a vein found to be fully thrombosed, but the recanalization was so complete that sufficient blood flow through it allowed efficient dialysis for 18 months while the patient was maintained on phenindione. Nevertheless, this is not always the rule. The function is poor in cases where the wall of the vessel becomes rigid because of the calcium and iron deposits and inflammation. Over a period of time their function steadily deteriorates. Calci- fication of the arterial wall in patients on regular haemodialysis is due to tertiary hyperparathyroidism, vitamin $\mathrm{D}$ intake, and administration of calcium exchange resins in high doses. Two of our patients recently had total parathyroidectomy because of hypercalcaemia. Apart from those patients who are indiscrete with their diet, patients on dialysis are now not on calcium exchange resins (Papadimitriou et al., 1968).

Verroust et al. (1968) reported that 19 out of their 23 patients on regular haemodialysis had normal or increased iron stores in the bone marrow. Some of these patients had received so many blood transfusions that, even if allowance was made for a rate of blood loss of $200 \mathrm{ml}$./month, they were unlikely to develop iron deficiency in less than 10 years. The authors concluded that attempts must be made to discontinue routine blood transfusions in such patients. The iron deposits we found on the arterial wall of the excised shunts was much more frequent in the old patients than in the new ones. Our policy now is not to give any blood to the patients on regular dialysis unless the packed cell volume is less than $20 \%$. We would prefer not to give any blood at all, but these patients have to be ready for transplantation at any time of the day or night when a cadaveric kidney becomes available.

We wish to thank Professor R. Shackman for permission to study these patients who were under his care. Thanks are due to Mrs. J. Mepham for preparing the histological sections.

Requests for reprints should be addressed to A. E. Kulatilake.

\section{REFERENCES}

Anderson, D. C., Martin, A. M., Clunie, G. J. A., Stewart, W. K., and Roberts, J.' S. (1968). Proceedings of European Dialysis and Transplant Association, 4, 55.

Carroll, R. N. P., Papadimitriou, M., and Kulatilake, A. E. (1969). In preparation.

Glashan, R. W., and Walker, F. (1968). British fournal of Surgery, 55, 189.

Kjellstrand, C. M. Lindergard, B., and Boijsen, E. (1968). Proceedings of European Dialysis and Transplant Association, 4, 61.

Kulatiliake, A. E. (1966). British Fournal of Urology, 38, 629.

Kulatilake, A. E. (1968). Proceedings of European Dialysis and Transplant Association, 4, 369.

McGee-Russell, S. M. (1958). Fournal of Histochemistry and Cytochemistry, 6. 22 .

Moore, G. W. (1951). Bulletin of the Institute of Medical and Laboratory Technicians, 9, 105.

Papadimitriou, M., Gingell, J. C., and Chishołm, G. D. (1968). Lancet, 2, 948.

Papadimitriou, M., and Kulatilake, A. E. (1969). Medical and Biological Engineering. In press.

Pendras, J. P., and Erickson, R. V. (1966). Annals of Internal Medicine, 64, 293.

Perls, M. (1867). Virchows Archiv für pathologische Anatomie und Physiologie und für klinische Medizin, 39, 42.

Sampson, D., Papadimitriou, M., and Kulatilake, A. E. (1969). In preparation.

Shaldon, S. (1966). Postgraduate Medical fournal, 42, Nov. Suppl., p. 9. Verroust, P. J., et al. (1968). Proceedings of European Dialysis and Transplant Association, 4, 12.

Wing, A. J., Curtis, J. R., and de Wardener, H. E. (1967). British Medlcal fournal, 3, 143. 
M. PAPADIMITRIOU ET $A L .:$ CLOTTING PROBLEMS WITH THE TEFLON-SILASTIC ARTERIOVENOUS SHUNT

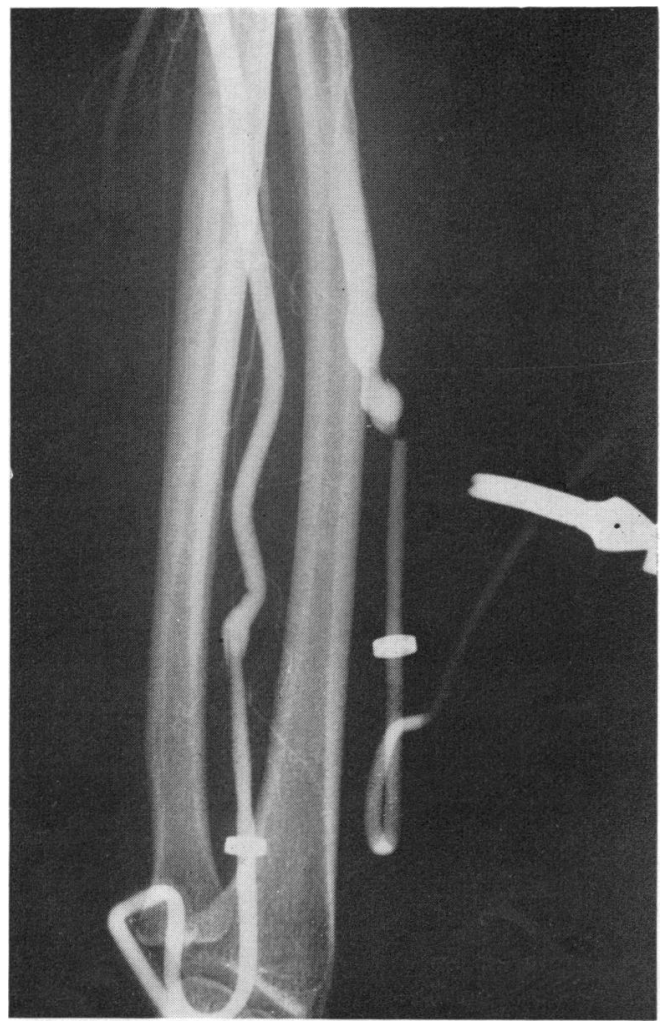

FIG. 1. - Arterioveno-

graphy showing the displacement of the Teflon tip.
FIG. 2.- Typical stenosis
of the vein near the Teflon tip.
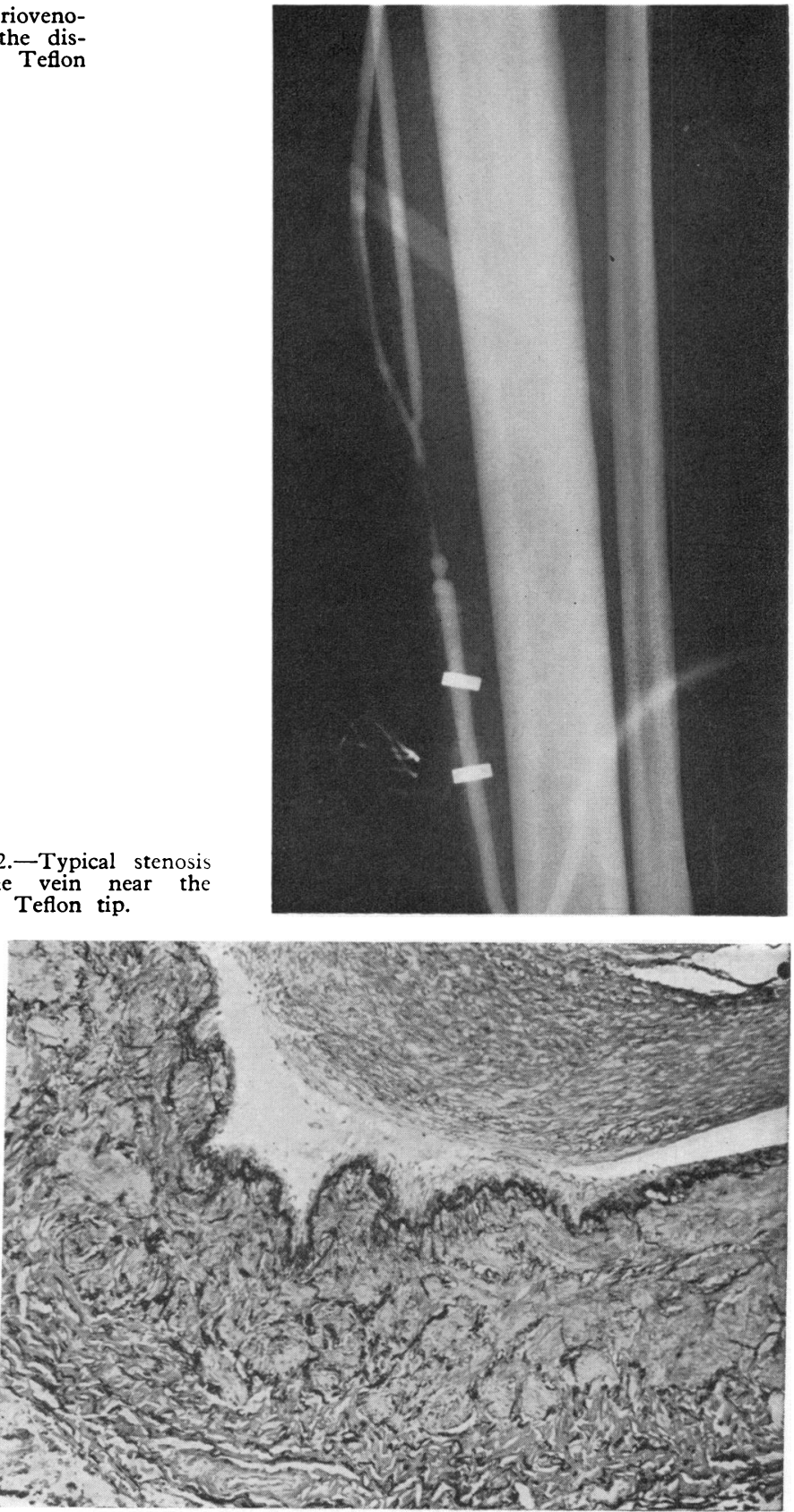

FIG. 5

FIG. 3.- Thickening of the intima and broken endothelium of the arterial side of an arteriovenous shunt.

$$
(\mathrm{H} \text {. and } \mathrm{E} . \quad \times 80 \text {.) }
$$

FIGS. 4 and 5.-Rupture and disfigurement of the elastic lamina of the arterial side of the arteriovenous shunt. (Weigert's elastic stain. $\times 80$.) 
M. PAPADIMITRIOU ET $A L .:$ CLOTTING PROBLEMS WITH THE TEFLON-SILASTIC ARTERIOVENOUS SHUNT

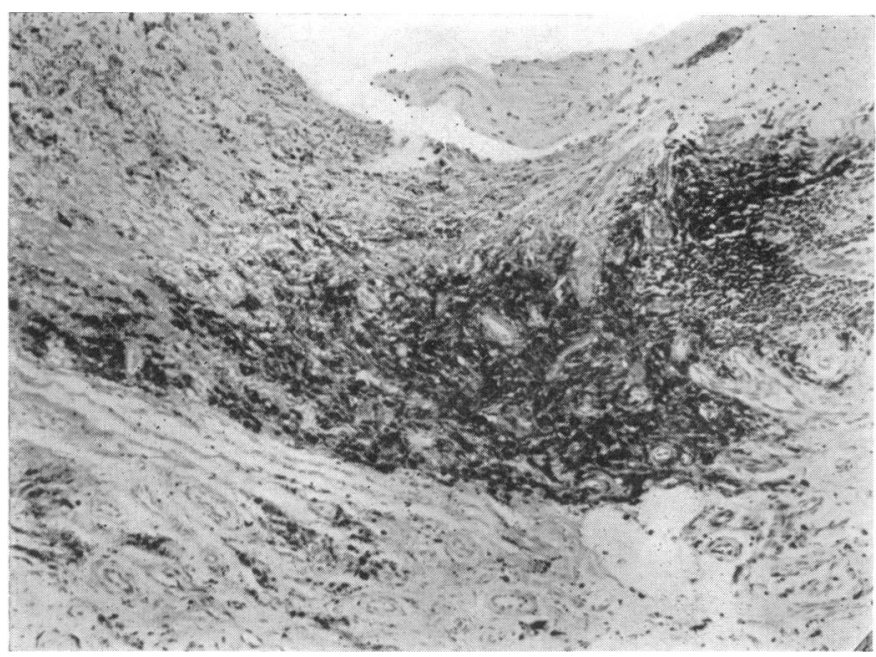

FIG. 6.-Iron deposits on the arterial wall of a long-standing arteriovenous shunt. (Perls's Prussian blue. $\times 80$.)

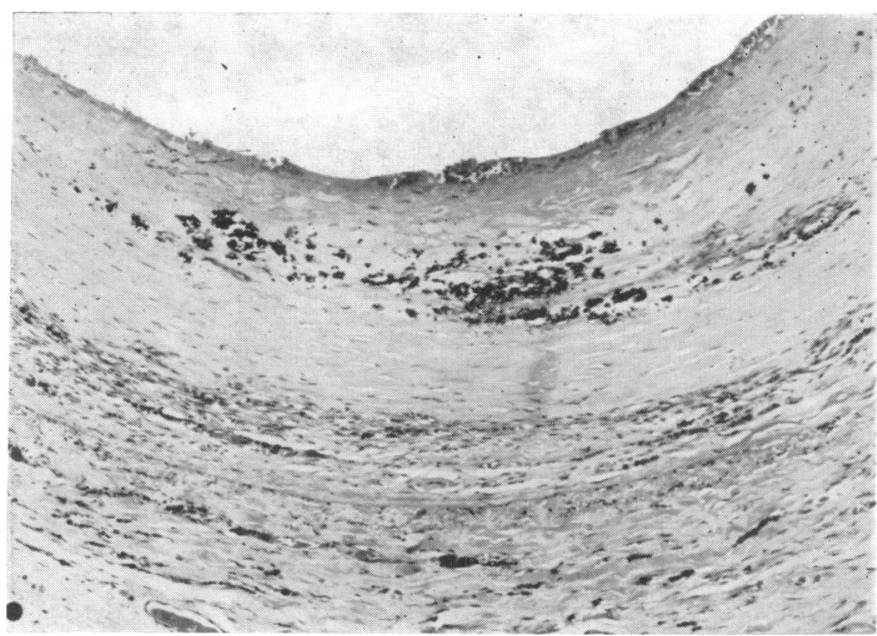

FIG. 7.-Calcium deposits on the arterial side of a long-standing arteriovenous shunt. (Alizarin red $\mathrm{S}$. $\times 80$.)

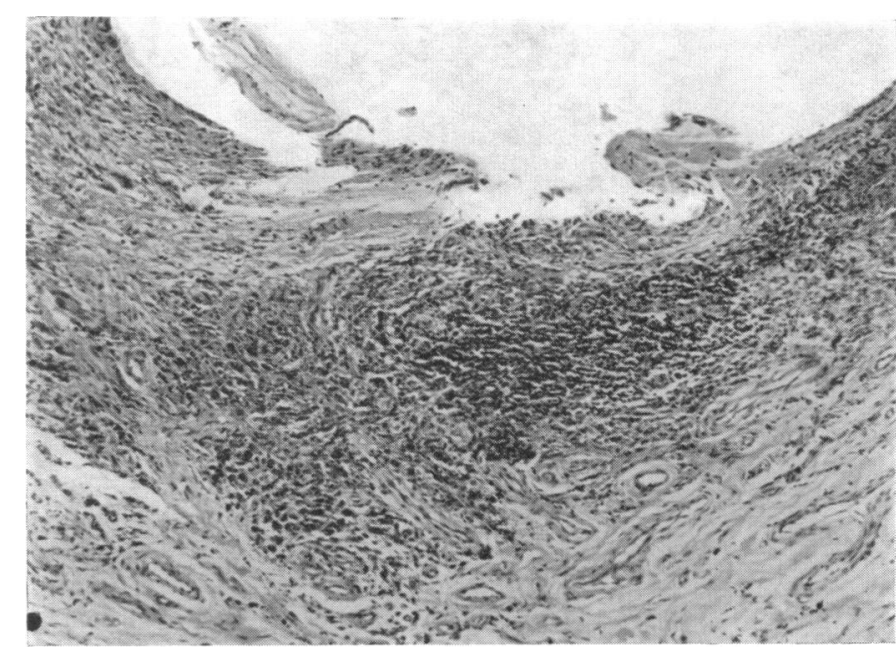
FIG. 9.- Chronic inflammatory cells infiltrating the wall of the venous
side of an arteriovenous shunt. (H. and $\mathrm{E} . \quad \times 80$.)

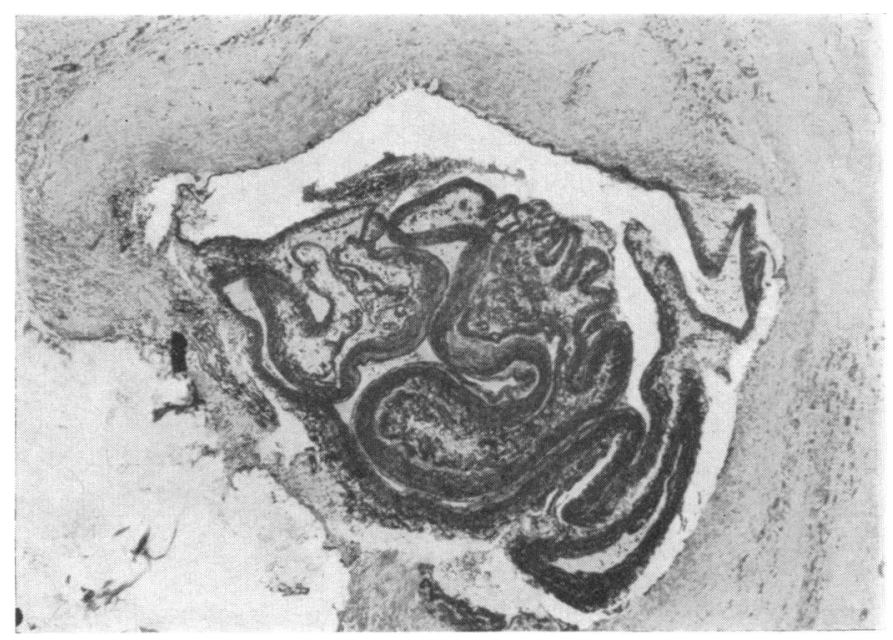

FIG. 11.- Stripping of the intima and recanalization of the venous side
FIG. 10.-Foreign-body-type granuloma and inflammatory reaction FIG. 10.-Foreign-body-type granuloma and inflammatory reaction
around the ligature at the venous side of an arteriovenous shunt. $(\mathrm{H}$. and
E. $\times 80$.
FIG. 11.- Stripping of the intima and recanalization of the venous side
of an arteriovenous shunt. $(\mathrm{H}$. and $\mathrm{E} . \times 32$. 